\title{
Towards revised physically based parameter estimation methods for the Pitman monthly rainfall-runoff model
}

\author{
Evison Kapangaziwiri* and Denis A Hughes \\ Institute for Water Research, Rhodes University, PO Box 94, Grahamstown 6140, South Africa
}

\begin{abstract}
This paper presents a preliminary stage in the development of an alternative parameterisation procedure for the Pitman monthly rainfall runoff model which enjoys popular use in water resource assessment in Southern Africa. The estimation procedures are based on the premise that it is possible to use physical basin properties directly in the quantification of the soil moisture accounting, runoff, and recharge and infiltration parameters. The results for selected basins show that the revised parameters are at least as good as current regionalised sets or give satisfactory results in areas where no regionalised parameters exist.
\end{abstract}

Keywords: hydrological modelling, Southern Africa, parameters, regionalisation, uncertainty

\section{Introduction}

The reliable quantification of hydrological variables is a prerequisite for sustainable water resource management, planning and development within basins. In Southern Africa this is not easy given the problem of data paucity as a result of shrinking measurement networks due to economic and manpower problems (Hughes, 1997; Oyebande, 2001). This means that most of the basins are virtually ungauged leading to uncertainty in the design of water resource systems. However, in spite of these problems water resource developments must continue to take place to satisfy the economic and social development needs of communities (Mazvimavi, 2003). The current impetus in hydrology is improving methods that enable hydrological predictions to be made in basins with limited or no historical measurement records and the reduction of the uncertainties associated with these predictions (Sivapalan et al., 2003).

The Pitman model (Pitman, 1973) has been used extensively for water resource assessment in Southern Africa (Midgley et al., 1994; Hughes, 1997; SWECO, 2004; Hughes et al., 2006). The original model was developed in 1973 by WV Pitman, but the version applied for the present study has undergone a number of modifications, the most substantial of which being the addition of revised procedures for simulating the interaction between surface and groundwater (Hughes, 2004a; Hughes and Parsons, 2005). Based on the success of the Pitman model when used in many basins of varying characteristics across Southern Africa during the FRIEND (Flow Regimes from International Experimental Network Data) project (Hughes, 1997), there is a need to further explore its use in other parts of the region. One of the objectives of such a study would be to develop regional parameter sets similar to those established during the South African water resources assessment project of the 1990s (Midgley et al., 1994). This is a practical solution for water resource managers who are often called upon to make hydrological predictions in data-scarce areas for long-term, often highly capital-

* To whom all correspondence should be addressed. 용 +27 46 622-4014; fax: +27 46 622-9427;

e-mail: evison@iwr.ru.ac.za

Received 16 October 2007; accepted in revised form 30 January 2008. ised water resource development projects. However, the success of the regional application of the model depends on the development of, among other things, parameterisation procedures that depend less on observed records whose integrity is often dubious. Previous work on the regionalisation of the parameters of the Pitman model has been based on either statistical analysis of calibrated parameter values against some measurable basin attributes or some form of parameter mapping based on assumptions of regional hydrological homogeneity (Midgley et al., 1994; Hughes, et al., 2006). While these methods have the potential to produce reasonable results, there are often limited observed streamflow data that can be used to establish the calibrated parameter sets. There is also uncertainty linked to how representative the available records are of the natural hydrology given the existence of upstream influences in most basins

This paper describes the preliminary development of an alternative parameter quantification approach based on the physical attributes of a basin. It addresses the question of whether physical basin properties and the role they play in runoff generation can be used directly in the estimation of parameter values. This would greatly enhance the application of the model in both gauged (through calibration) and ungauged (through regionalisation) basins. Only the soil -moisture accounting, runoff, recharge and surface infiltration parameters are considered. The motivation for this type of estimation procedure is that the model is soundly based in conceptual hydrology and the parameters are physically interpretable, hydrometeorological and hydrogeological data are available from various studies and collected by various agencies in the region that can be used for hydrological modelling, and the advent of GIS and remotesensing techniques can aid in the collection and processing of physical basin property data. The study may also provide further direction and incentive for the collection and processing of physical basin property data and identify the type of data that needs to be collected for hydrological modelling. It is hoped that this approach will result in a more consistent parameterisation of the Pitman model and, therefore, enhance its application in ungauged basins and regionalisation. This paper briefly discusses the ungauged problem, and then looks at the different regionalisation techniques before giving a brief synopsis of the 
Pitman model. The results from test case studies are presented as well as a brief discussion and the conclusions of this initial phase of the study.

\section{The ungauged problem}

By definition, an ungauged basin is one with inadequate hydrological observations to enable the computation of hydrological variables at a level of accuracy acceptable for practical water resource management (Sivapalan et al., 2003). This includes the quality and quantity of the data and the scale, both temporal and spatial, at which the computations are required. While large and strategic basins may have sufficient hydrometric stations for the determination of streamflow, many small- to medium-sized basins are usually less endowed with gauging equipment. In some basins the existing gauging networks are being discontinued mainly due to past and present economic and political constraints (Hughes, 1997; Oyebande, 2001). Thus, large parts of Southern Africa are virtually ungauged. Unfortunately, waterrelated developments such as dam construction, irrigation development, etc., still have to take place in such data-scarce situations and hydrologists are often called upon to generate realistic water resource information.

For a concerted, global approach from the scientific community to the problem of ungauged basins, the International Association of Hydrological Sciences (IAHS) adopted 2003 - 2012 as the Predictions in Ungauged Basins (PUB) decade aimed at identifying a major breakthrough in the theoretical foundations of modelling and a critical examination of the existing approaches to hydrological predictions. The main objective of PUB is to move away from calibration-based modelling towards 'understanding-based methods' that would make predictions in ungauged basins simpler and less uncertain (Sivapalan et al., 2003).

\section{Parameter regionalisation}

For ungauged basins, the problem of model and parameter uncertainty is acute, as no data are available to constrain predictive uncertainty. Hydrological predictions in ungauged basins have commonly been achieved through the extrapolation of information from gauged basins in a process known as regionalisation (Nathan and McMahon, 1990). The basic tenet in regionalisation is that, if relationships exist between calibrated model parameters and catchment physical properties that hold for gauged basins, then flow simulations could be achieved in ungauged basins with similar physical attributes. The most common basin attributes that have been used include climate, topography, vegetation, soil properties (Chiew and Siriwardena, 2005), annual rainfall, areal potential evapotranspiration (Boughton and Chiew, 2006), basin area and geology. There are various means by which regionalisation is achieved but they all tend to fall into one of the following groups:

- Statistical methods in which bivariate or multivariate linear and non-linear regression relationships are developed between optimised model parameters and some basin attributes for a number of gauged basins and are then transferred to the ungauged basin (Boughton and Chiew, 2006). The calibrated parameters may reflect input data errors as well as true signals related to variations in basin properties and that makes the parameters unstable. Parameter interactions and non-unique parameter sets suggest that the resulting relationships may be partly a reflection of the cali- bration approach which may often contain some degree of subjectivity. Also some of the parameters may not be easy to estimate as a result of a lack of a concise physical interpretation (Hughes, 1982).

- Parameter mapping which involves fixing model parameters to average values for the region. The premise is that regions that exhibit the same hydrological response to rainfall input would of necessity have the same parameters even though results have not always been positive (Merz and Bloschl, 2004). The use of a priori values has delivered better results (Wagener et al., 2006). The parameter values are assigned based on a similarity measure of basins using soils, rainfall, runoff ratios, etc. Homogeneous basins are identified based on some selected group-defining signatures (Nathan and McMahon, 1990). One of the most common measures has been geographical proximity which assumes that catchments that are in close proximity to each other would have a similar runoff regime since climate and catchment properties vary smoothly in space (Merz and Bloschl, 2004). The parameterisation of the so-called quaternary catchments in South Africa (Midgley et al., 1994) and the regionalisation of the HBV (Hydrologiska Bryåns Vattenbalansavdelning) in Sweden (Bergstrom, 2006) were both achieved by mapping parameters from gauged to ungauged basins on the basis of similar basin physical properties and hydrological response.

Testing regionalisation approaches of necessity requires that a part of the gauged database be reserved to validate the regional parameter estimations. This means that the data set used to establish the regionalisation is reduced in size. This is a problem in areas with a limited number of gauged catchments such as Southern Africa. This necessitates the development of regionalisation procedures that are less reliant on calibration parameters.

Regionalisation studies have met with limited success (Franks, 2002). The problems that seem to haunt all the studies are equifinality and parameter interactions (Beven, 2001). It has not been easy with most regionalisation methods to be sufficiently confident that all the necessary and dominant controls of catchment behaviour have been captured in the regionalisation process. The regression equations derived from perceived relationships between catchment characteristics and model parameters are empirical and therefore cannot be expected to be universally applicable, even in apparently similar basins. Significant bias exists in calibrated parameters due to observation error and model process uncertainty that permeate the derived regionalisation techniques. This hinders the derivation of robust relationships on which ungauged basins can be confidently parameterised and subsequently leads to high predictive uncertainty for ungauged catchments (Franks, 2002). Direct estimation of parameter values from physical basin attributes is more desirable in that it reduces the ambiguity in parameter estimation by calibration based only on the runoff signal at the basin outlet. Ao et al. (2006) suggest the following five aspects as prerequisites:

- Model parameters should have exact physical meanings

- Availability of a large amount of spatial physical property data

- Establishment of relationships between basin property data and parameter values

- Establishment of parameter-basin characteristic transfer functions

- Use of GIS techniques. 


\section{Parameter estimation procedures for the Pitman model}

\section{The conceptual framework}

The detailed structure of the model is not repeated here and the reader is referred to previous publications (Pitman, 1973; Midgley et al., 1994; Hughes, 2004). The model comprises three conceptual storages (interception, soil moisture and groundwater) and simulates infiltration-excess flow, saturation-excess flow, direct overland flow and groundwater flow. It is a conceptual, semi-distributed, monthly rainfallrunoff model that uses monthly rainfall data and monthly estimates of evapotranspiration as input. The groundwater version of the Pitman model (Hughes, 2004), used in this study, has explicit groundwater routines and is quite heavily parameterised. Some physical interpretation of the parameters, setting the conceptual framework for the estimation procedures, precedes the descriptions of the estimation procedures. This study focused initially on the soil moisture accounting, subsurface runoff, recharge and the soil surface infiltration parameters.

Figure 1 illustrates the regionalisation approaches that have been used for the Pitman model. A number of equally good parameter sets could be achieved by calibration (Fig. 1A), exemplifying the problem of equifinality which is discussed in detail by Beven (1993, 2001). This may in part be explained by unknown parameter interactions within the model as a result of the large number of parameters, or by different model users concentrating on different aspects of the model. The process of regionalisation proceeds with the collection of a set of physical basin properties. These may be used to derive statistical relationships with the calibrated parameters (quantitative approach, e.g. Hughes, 1982; Mazvimavi, 2003), or to determine measures of similarity for parameter mapping (qualitative approach, e.g. Midgley et al., 1994; Hughes et al., 2006). The problem is that different calibration approaches will lead to different regionalisation schemes, introducing additional uncertainty in the use of the model in ungauged basins.

This paper proposes that if it is possible to constrain the parameter estimation using physical basin properties earlier on in the calibration process (Fig. 1B), then the regionalisation process and the application of the model in ungauged basins would be more objective. This is largely because subjectivity in the calibration process will be reduced through this approach.

\section{Estimating the moisture storage parameter ST}

The moisture storage component of the Pitman model is controlled by a parameter ST, the maximum subsurface storage which is depleted by evaporative losses, runoff and recharge to the groundwater store. In this study ST is assumed to represent moisture stored not only in the soil but also within the zone of intermittent saturation below the soil and above the water table. This zone, made up of fractured rock systems, is believed to play an important part in subsurface flow generation in some catchments within Southern Africa and the ST parameter must therefore account for the moisture storage potential of these fractures. Thus, the model variable S (with a maximum of ST) is made up of a combination of the moisture stored in the soil $\left(\mathrm{ST}_{\text {soii }}\right)$ as well as the storage in the fracture zone $\left(\mathrm{ST}_{\text {unsat }}\right)$ that has the potential to contribute to interflow. These 2 components are estimated separately.

$\mathrm{ST}_{\text {soil }}$ represents the moisture store in the soil at saturation and its value is estimated by the equation:

$$
\mathrm{ST}_{\text {soil }}(\mathrm{mm})=\operatorname{POR}(\%) * \operatorname{VVAR}(\%) * \text { Soil depth }(\mathrm{m}) / 10
$$

where:

POR represents the soil porosity and therefore a measure of the moisture holding capacity

VVAR represents a correction factor for vertical variations in porosity

The porosity used in this study is a mean area-weighted value for the basin based on soil- texture classes and the values are quite similar to those obtained from previous studies that have related porosity to the percentage distribution of sand, clay and silt within different texture classes (USDA, 1969; Rawls et al., 1982; Schulze et al., 1985). The soil depth is estimated as a mean from the percentage areas of the basin occupied by three main topographic units (upper slope, mid slope and valley bottom). 


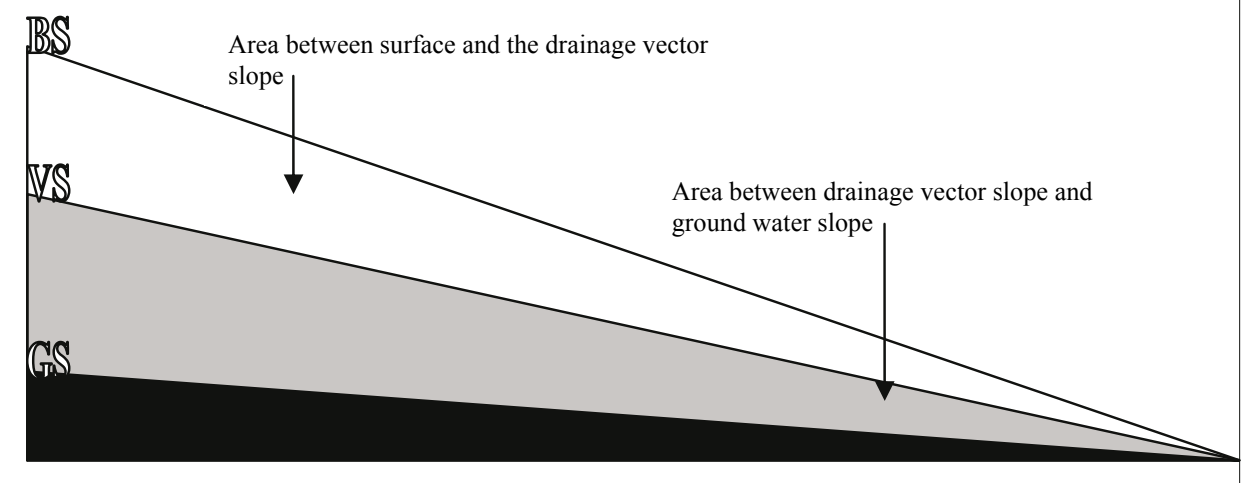

Figure 2

Conceptualisation of the subsurface drainage that determines the interflow process from the unsaturated zone

The unsaturated zone component $\left(\mathrm{ST}_{\text {unsat }}\right)$ will be influenced by the storativity (S) of the underlying geological formation and the depth to the water table (DGW). This study assumes that percolating water would have 2 directional components - a vertical one contributing directly to recharge of the saturated groundwater zone and a lateral one with the potential to re-emerge at springs or seeps, which occur at elevations above the regional groundwater level. Horizontally aligned fractures or perched aquifers associated with layers of lower permeability can account for the lateral water movement. The vector result of these 2 components is referred to here as the drainage vector slope (VS in Fig. 2). VS depends on geology, with steeper gradients being prevalent in highly permeable rock masses with no impermeable layers or lenses. For unsaturated flow to re-emerge as spring-flow, VS must be less than the mean basin slope. The ratio of the volume that lies between the basin surface slope (BS in Fig. 2) and the drainage vector slope (VS) to the total unsaturated volume represents the proportion of the unsaturated zone that can contribute to unsaturated flow. The area between the drainage vector slope and the groundwater slope (GS) will not be able to contribute to unsaturated flow at the surface, but will contribute to aquifer recharge.

$\mathrm{ST}_{\text {unsat }}$ is thus estimated as follows:

$$
\begin{aligned}
& \text { If } \mathrm{BS}>\mathrm{VS} \text { then: } \\
& \quad \mathrm{ST}_{\text {unsat }}(\mathrm{mm})=\mathrm{DGW}(\mathrm{m}) * 1000 * \mathrm{~S} * \text { Ratio } \\
& \text { with } \\
& \quad \text { Ratio }=[\operatorname{Tan}(\mathrm{BS})-\mathrm{Tan}(\mathrm{VS})] /[\mathrm{Tan}(\mathrm{BS})-\operatorname{Tan}(\mathrm{GS})] \\
& \text { and if } \mathrm{BS} \leq \mathrm{VS} \text { then: } \\
& \quad \mathrm{ST}_{\text {unsat }}(\mathrm{mm})=0
\end{aligned}
$$

\section{Estimating runoff from the moisture store FT}

Runoff from the moisture store is simulated using a non-linear relationship between discharge and soil moisture content. FT refers to the interflow generated when the moisture level (S) is at its maximum value (ST). It has been assumed in the physical interpretation of ST that it can represent both soil moisture and unsaturated zone storage, therefore FT must represent the maximum possible runoff from these 2 sources (given as $\mathrm{FT}_{\text {soil }}$ and $\mathrm{FT}_{\text {unsat }}$ respectively). For purely Darcian flow, subsurface lateral drainage occurs only at moisture contents close to saturation but this is rather simplistic and generally inapplicable when considering the basin scale. Given the likely spatial variations in moisture content within a basin, subsurface lateral flow is likely to occur within a basin over a wide range of average basin moisture contents and this concept is used in this study. As with ST, the 2 components of FT are also estimated separately.

$\mathrm{FT}_{\text {soil }}$ is the maximum subsurface outflow when the basin soils are at saturation and is assumed to occur through the banks of the active channel, and the contributing area $\left(\mathrm{CA}\right.$, in $\left.\mathrm{km}^{2} \cdot \mathrm{km}^{-2}\right)$ is given by:

$$
\mathrm{CA}=2 * \mathrm{DD}\left(\mathrm{km} \cdot \mathrm{km}^{-2}\right) * \text { soil depth }(\mathrm{m}) / 1000
$$

where:

DD refers to the drainage density of the basin

The monthly depth of interflow from the soil $\left(\mathrm{FT}_{\text {soil }}\right.$, in $\mathrm{mm} \cdot \mathrm{month}^{-1}$ ) was thus assumed to be adequately explained as a function of CA, the saturated hydraulic conductivity of the basin soils, $\mathrm{K}\left(\mathrm{m} \cdot \mathrm{d}^{-1}\right)$ and the mean basin slope (BS) and expressed as follows:

$$
\mathrm{FT}_{\text {soil }}=\mathrm{CA} * \mathrm{~K} * \mathrm{BS} * 30 * 1000
$$

The estimation approach for $\mathrm{K}$ is based on area-weighted soil texture classes plus some adjustments to account for macro-pore development, organic content, structural development and sand grade (Hughes and Sami, 1994). Cosby et al. (1984) suggested typical means and ranges of hydraulic conductivity values for different soil types and these were used as a guide in this study. The actual values of $\mathrm{K}$ used in this study are based on the various factors that operate at a basin scale using the following relationship:

$$
\mathrm{K}\left(\mathrm{m} \cdot \mathrm{d}^{-1}\right)=\mathrm{e}^{\left(\mathrm{P}^{*} 0.55-0.054\right)}
$$

where:

PI is a permeability index value estimated from soil characteristics (texture, level of macro-pore development, organic content, structural development and sand grade of the soil)

Estimating the outflow from the unsaturated zone $\left(\mathrm{FT}_{\text {unsat }}\right)$ proved more difficult given the paucity of documentation of the physical concepts of subsurface runoff generation from this zone. Figure 2 represents a conceptual diagram that is independent of the actual processes occurring. The lateral component contributing to the drainage vector may be the result of water flowing in horizontal, or near horizontal, fractures or a series of overlapping layers of material with low permeability creating perched water tables and allowing lateral saturated flow to develop. The estimation approach adopted is given by: 


$$
\mathrm{FT}_{\text {unsat }}(\mathrm{mm})=2 * \mathrm{DD} * \mathrm{~T} * \mathrm{VS} * 30 / 100
$$

where:

$\mathrm{T}\left(\right.$ in $\mathrm{m}^{2} \cdot \mathrm{d}^{-1}$ ) represents the effective transmissivity chosen as a sub-basin average and accounts for variability in the geology

Based on literature, the values used in estimation procedures varied between 0.5 and $5 \mathrm{~m}^{2} \cdot \mathrm{d}^{-1}$.

\section{Estimating the power (POW) of the moisture-runoff relationship}

The power (POW) of the relationship between subsurface outflow and the amount of moisture (S) in a basin was assumed to be made up of the 2 components associated with the soil water and the unsaturated zone runoff. POW represents the shape of the relationship that determines reduced runoff (relative to the maximum) as the moisture contents of the soil zone and unsaturated zone decrease. In the soil zone the relationship is likely to be mainly influenced by patterns of moisture redistribution following rainfall events and how these patterns affect the distribution of saturated areas. It is therefore reasonable to suggest that, for any given mean basin moisture content (S), the spatial variation could be represented by a frequency distribution. At the extreme ends of the moisture content spectrum, i.e. when the basin is either very dry or close to saturation, this variability must be low. The variability would be highest at moderate moisture contents. Given detailed field observations the spatial variation of moisture content could be adequately defined for a range of basin mean moisture contents. However, in the absence of detailed field data, a simpler approach was adopted based on the probability distributed principle of Moore (1985) and similar to the procedures used within the VTI model (Hughes and Sami, 1994).

The concept is illustrated in Fig. 3. The four lines represent cumulative Normal distribution frequency curves for mean basin moisture contents of 0.2 to 0.8 , each having a different standard deviation. If a relative moisture content of 0.9 is assumed to represent the threshold for lateral flow, Fig. 3 indicates that the percentage of the basin area contributing to runoff would vary from $0 \%$ (at mean of 0.2 ) to $60 \%$ at a mean of 0.8 (triangle symbols). If a method of estimating the variation in the standard deviation with mean moisture content can be found, it follows that a relationship between mean moisture content and relative runoff (i.e. runoff relative to the maximum at full basin saturation) can be developed. The principles of such a method should be that the standard deviation will be at a maximum at moderate moisture contents and at a minimum for both low and high moisture contents.

The resulting relationship between mean relative basin moisture content and relative runoff is then identical to the format of the Pitman model 'soil' moisture runoff function if this is expressed in non-dimensional terms (i.e. $\mathrm{S} / \mathrm{ST}_{\text {soil }}$ for the horizontal axis and $\mathrm{Q} / \mathrm{FT}_{\text {soil }}$ for the vertical axis - see Fig. 4). It is assumed that the maximum standard deviation (SDEV) at a

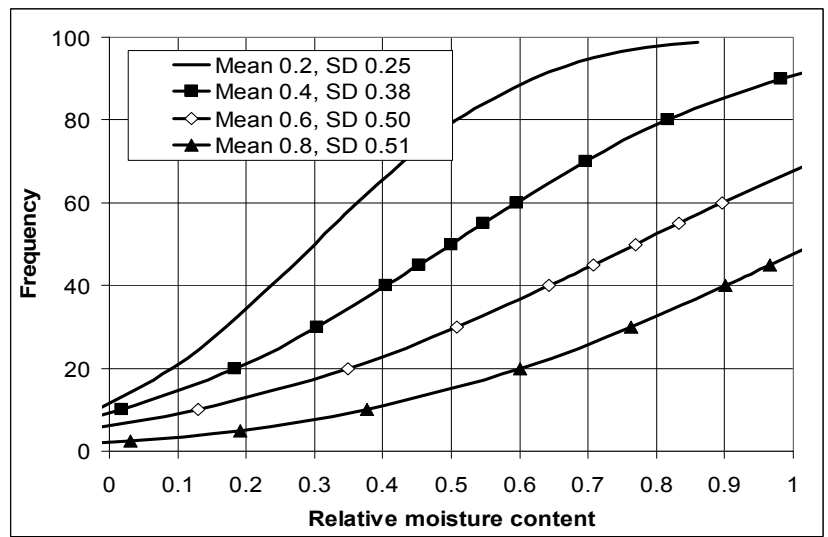

Figure 3

Illustration of the concept of using a frequency distribution to describe the spatial distribution of soil moisture for different mean moisture contents.
Figure 4

Runoff-moisture content relationships for four conditions (defined by the moisture distribution parameter, SDEV).

The basin conditions represented are steep slopes and well-drained soils $(A)$, moderate slopes and moderately well-drained soils $(B)$, moderate slopes and moderately poorly drained soils $(C)$ and gentle slopes and poorly drained soils $(D)$.
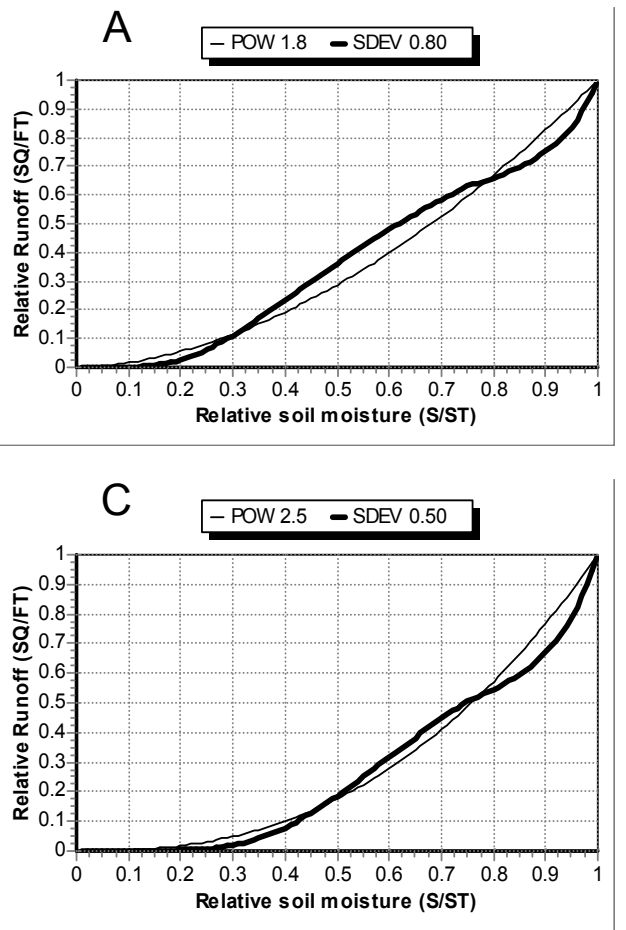

B
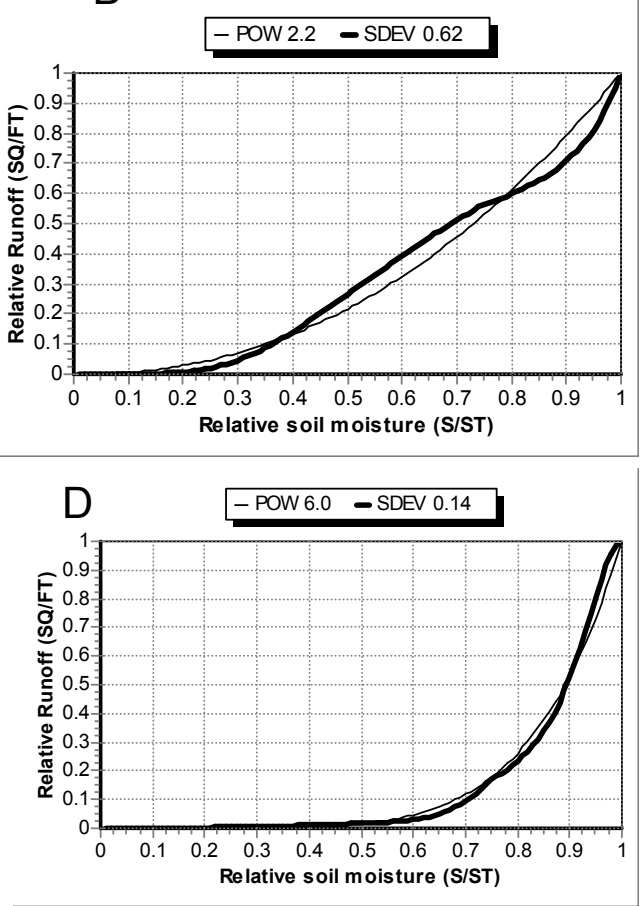

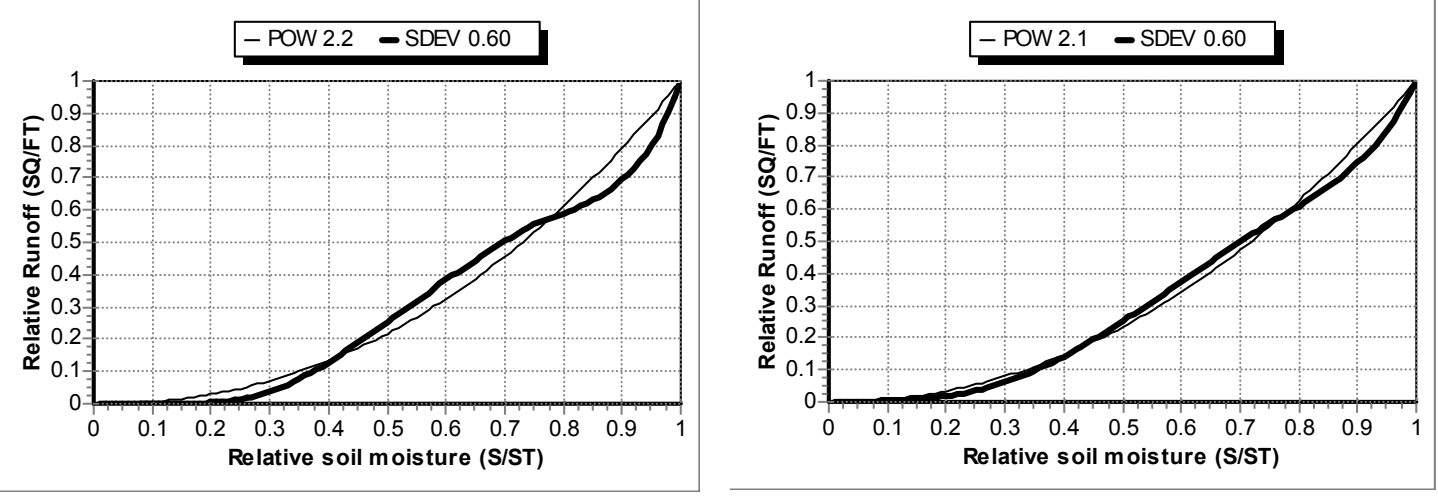

Figure 5

Runoff-moisture

content relation-

ships for the

same basin

without $F T$

(left side) and

with $F T_{\text {unsat }}$ (right

side). The value

of $F T_{\text {unsat }}$ is 6.1

$\mathrm{mm}$ and $\mathrm{F} T_{\text {soil }}$ is

$8.0 \mathrm{~mm}$. mean moisture content of 0.75 can be established from the physical attributes of the basin. Low values would be expected when there is little spatial variation in moisture content, which may occur in areas of low topography and poorly drained soils. High values of SDEV are expected in steep topography with well drained soils on the hill slopes and less well drained soils in the valley bottoms. These concepts are represented in Fig. 4 and appropriate values of POW in the Pitman model function $(\mathrm{Q} / \mathrm{FT}$ $\left.=(\mathrm{S} / \mathrm{ST})^{\mathrm{POW}}\right)$ have been manually fitted to reproduce similarly shaped curves.

The contribution of the unsaturated zone to the total interflow is incorporated in the estimation using the largely arbitrary (in the absence of more information) assumption that the shape of the unsaturated curve can be defined by:

$$
\mathrm{Q}_{\text {unsat }} / \mathrm{FT}_{\text {unsat }}=\left(\mathrm{S}_{\text {unsat }} / \mathrm{ST}_{\text {unsat }}\right)^{2}
$$

where:

$\mathrm{Q}_{\text {unsat }}$ represents the runoff from the unsaturated zone at a mean moisture content of $\mathrm{S}_{\text {unsa }}$

The full estimation approach generates the 2 curves (soil and unsaturated zones) separately and then adjusts both to ensure that the ordinates range between 0 and 1 . The adjustment is based on the relative contributions to total runoff of the 2 zones (i.e. $\mathrm{FT}_{\text {soil }}$ and $\mathrm{FT}_{\text {unsat }}$ ). Figure 5 illustrates the effect of excluding and including $\mathrm{FT}_{\text {unsat }}$ in the estimation. There is not a large difference in this case but it is expected that in areas where the contribution of the unsaturated zone is high its exclusion would lead to errors in the estimation of POW.

A single value of $\mathrm{S}$ (mean moisture content) is calculated in each time step of the model and this represents both the soil and unsaturated zones. In practice the mean moisture contents of these zones would not vary with the same pattern (the unsaturated zone would tend to lag behind changes in the soil zone). However, to incorporate such a modification would require substantial changes to the model structure, which is not the purpose of this study.

\section{Estimating the recharge (HGGW) and power (GPOW) of the relationship between recharge and moisture storage}

The approach to estimating HGGW and GPOW could follow similar principles to those used for $\mathrm{FT}_{\text {soil }}$ and POW. There are, however, existing estimates of mean annual recharge available for some Southern African basins which can be used to guide the calibration of HGGW. GPOW will be similarly calibrated and results compared against observed low flows where available. These approaches are considered to be adequate at this stage of the development of the parameter estimation procedures.

\section{Estimating the parameters of the basin absorption function (ZMIN and ZMAX)}

The infiltration parameters describe the absorption capacity of the catchment in response to different rates of rainfall input. The model makes use of a non-symmetrical triangular distribution of catchment absorption rates varying from a minimum value of ZMIN to a maximum value of ZMAX with an average of ZAVE. The approach taken for the design of a physically based procedure makes use of both basin soil-surface conditions and hydrometeorological factors. The basic tenet of this approach is to use soil properties to define the parameters of a modified form of the Kostiakov equation (Hughes and Sami, 1994), basin hydrometeorological characteristics to disaggregate monthly rainfall and to apply the infiltration equation to estimate surface runoff for a range of monthly rainfalls. The parameters ZMIN, ZAVE and ZMAX of the surface runoff model algorithm are then manually fitted to match the infiltration equation based estimates of runoff for different monthly rainfalls. It was noted that it was necessary to include an estimate of the likely extent of saturation excess surface runoff, as well as infiltration excess runoff in the estimations approach. This issue requires further investigation as the model algorithm does not explicitly account for saturation excess surface runoff.

\section{Results from case studies}

The study investigated a total of 71 basins from Southern Africa and the physical basin property data required for the estimation were available at various levels of detail. For the purposes of this paper, 8 gauged basins have been chosen to illustrate the revised parameter estimation procedures. Table 1 gives a brief description of the physical attributes of the basins.

The parameters estimated using physical basin property data and the results of model simulations are given in Table 2. In general the results are positive. For the South African basins, the results of model simulations based on physically based parameters were compared against those of the current regionalised parameters for the same inputs, most of which were taken from Midgley et al. (1994) and the additional parameters related to the groundwater functions (Hughes, 2004) are adaptations based on the Groundwater Resources Assessment Project of the Department of Water Affairs and Forestry (2005). Nash and Sutcliffe's coefficient of efficiency was used to measure performance of the model for both the normal (CE) and the log-transformed (CE (ln)) values in all the basins tested. Of the 30 South African basins investigated only 2 failed to produce results that were as good as the current regionalised parameter sets or better (e.g. 


\begin{tabular}{|l|l|l|l|}
\hline \multicolumn{4}{|c|}{ Physical descriptions of the basins used for illustration of the parameter estimation procedures } \\
\hline Country & Basin code & Gauge & Description \\
\hline South Africa & K20A & K2H002 & Steep topography, moderate-deep, permeable, sands; fractured quartzite. \\
\hline & G10E & G1H008 & $\begin{array}{l}\text { Steep topography, moderately deep, porous sandy loams with some impermeable lenses; } \\
\text { unconsolidated sedimentary strata. }\end{array}$ \\
\hline & V70D & V7H012 & $\begin{array}{l}\text { Steep topography, moderate to deep, clayey soils; interbedded mudstones, shales and } \\
\text { sandstones. }\end{array}$ \\
\hline & X31A & X3H001 & Steep topography, moderately deep sandy clay loams; dolomites and limestone. \\
\hline & H10A-C & H1H003 & Steep, moderately deep sandy loams; Karoo shales and sandstones. \\
\hline Zimbabwe & BS3 & B78 & Gentle topography, moderately deep sands; Karoo sandstones. \\
\hline & FH & F1 & Undulating topography, deep clays; fractured granites. \\
\hline Mozambique & Unknown & E73 & Undulating topography, deep sandy soils; granites- gneissic and massive. \\
\hline
\end{tabular}

\begin{tabular}{|c|c|c|c|c|c|c|c|c|}
\hline \multicolumn{9}{|c|}{$\begin{array}{r}\text { TABLE } 2 \\
\text { Results of model simulations using the phys }\end{array}$} \\
\hline Basin & K20A & G10E & V70D & X31A & H10A_C & B78 & F1 & EM73 \\
\hline MAP (mm) & 718 & 649 & 814 & 1243 & 590 & 575 & 1637 & 1574 \\
\hline Basin area $\left(\mathrm{km}^{2}\right)$ & 131 & 395 & 196 & 174 & 657 & 49 & 6.5 & 1100 \\
\hline \multicolumn{9}{|c|}{ WR90 parameters and model simulation results } \\
\hline ST & 100 & 250 & 120 & 600 & 180 & & & \\
\hline FT & 50 & 40 & 30 & 60 & 75 & & & \\
\hline POW & 2 & 2 & 3 & 2 & 2 & & & \\
\hline GW & 50 & 15 & 15 & 60 & 15 & & & \\
\hline ZMIN & 0 & 20 & 999 & 0 & 0 & & & \\
\hline ZMAX & 200 & 500 & 999 & 800 & 450 & & & \\
\hline CE / CE (ln) & $0.66 / 0.36$ & $0.77 / 0.74$ & $0.51 / 0.55$ & $0.67 / 0.47$ & $0.78 / 0.59$ & & & \\
\hline \multicolumn{9}{|c|}{ Basin property data, physically based parameters and model simulation results } \\
\hline Drainage density $\left(\mathrm{km} \cdot \mathrm{km}^{-2}\right)$ & 1.2 & 1.92 & 2.34 & 1.47 & 1.9 & 0.8 & 2.54 & 1.5 \\
\hline Mean basin slope (BS) $(\%)$ & 25 & 25 & 30 & 25 & 30 & 10 & 20 & 15 \\
\hline Regional GW slope (GS) (\%) & 5 & 5 & 5 & 5 & 3 & 2 & 5 & 2 \\
\hline Drain. vector slope (VS) (\%) & 3.1 & 3.1 & 4.2 & 3.1 & 3.1 & 4.2 & 4.2 & 4.2 \\
\hline Mean soil depth (m) & 1.2 & 0.8 & 0.8 & 1 & 1.2 & 0.9 & 2.2 & 2 \\
\hline FT soil depth (m) & 1.5 & 1.1 & 0.93 & 1.09 & 1.53 & 0.93 & 2.5 & 2.13 \\
\hline Soil porosity & 0.38 & 0.4 & 0.32 & 0.38 & 0.37 & 0.41 & 0.32 & 0.45 \\
\hline Vertical variation factor & 0.39 & 0.63 & 0.8 & 0.72 & 0.62 & 0.8 & 0.85 & 1 \\
\hline Soil permeability $\left.\left(\mathrm{m} \cdot \mathrm{d}^{-1}\right)\right)$ & 2.438 & 0.617 & 0.356 & 0.468 & 0.812 & 0.812 & 0.812 & 0.27 \\
\hline Depth to GW (m) & 10 & 15 & 15 & 10 & 30 & 30 & 10 & 20 \\
\hline GW storativity & 0.002 & 0.002 & 0.003 & 0.002 & 0.002 & 0.004 & 0.008 & 0.057 \\
\hline Unsat. transmissivity $\left(\mathrm{m}^{2} \cdot \mathrm{d}^{-1}\right)$ & 6 & 2 & 1 & 2.5 & 5 & 0.9 & 2 & 1.5 \\
\hline $\mathrm{ST}_{\text {soil }}(\mathrm{mm})$ & 178 & 202 & 205 & 274 & 275 & 295 & 598 & 900 \\
\hline $\mathrm{ST}_{\text {unsat }}(\mathrm{mm})$ & 18 & 30 & 45 & 20 & 6.5 & 87 & 80 & 949 \\
\hline $\mathrm{FT}_{\text {soil }}\left(\mathrm{mm} \cdot \mathrm{month}^{-1}\right)$ & 65.83 & 19.53 & 13.98 & 11.21 & 42.56 & 3.64 & 61.85 & 7.75 \\
\hline $\mathrm{FT}_{\text {unsat }}\left(\mathrm{mm} \cdot \mathrm{month}^{-1}\right)$ & 1.3 & 7.14 & 5.9 & 6.84 & 6.5 & 1.81 & 12.8 & 5.67 \\
\hline POW & 2.2 & 1.8 & 4 & 2 & 1.8 & 3.5 & 2.2 & 2.6 \\
\hline ZMIN (mm) & 20 & 10 & 30 & 0 & 10 & 20 & 20 & 0 \\
\hline ZMEAN (mm) & 160 & 210 & 300 & 375 & 110 & 340 & 285 & 350 \\
\hline ZMAX (mm) & 200 & 400 & 550 & 750 & 210 & 660 & 550 & 700 \\
\hline CE / CE (ln) & $0.75 / 0.63$ & $0.78 / 0.76$ & $0.60 / 0.75$ & $0.71 / 0.74$ & $0.75 / 0.72$ & $0.79 / 0.74$ & $0.70 / 0.71$ & $0.66 / 0.85$ \\
\hline
\end{tabular}

Fig. 6B). In many cases the revised parameter sets are quite different to existing South African regional sets. A general observation is that the revised values of the ST parameter were almost always higher than the WR90 values, while the FT values were almost always lower. The power values (POW) of the moistureinterflow relationship were generally similar. The differences in runoff generated by the soil moisture function were compensated for by differences in the surface runoff parameters. 


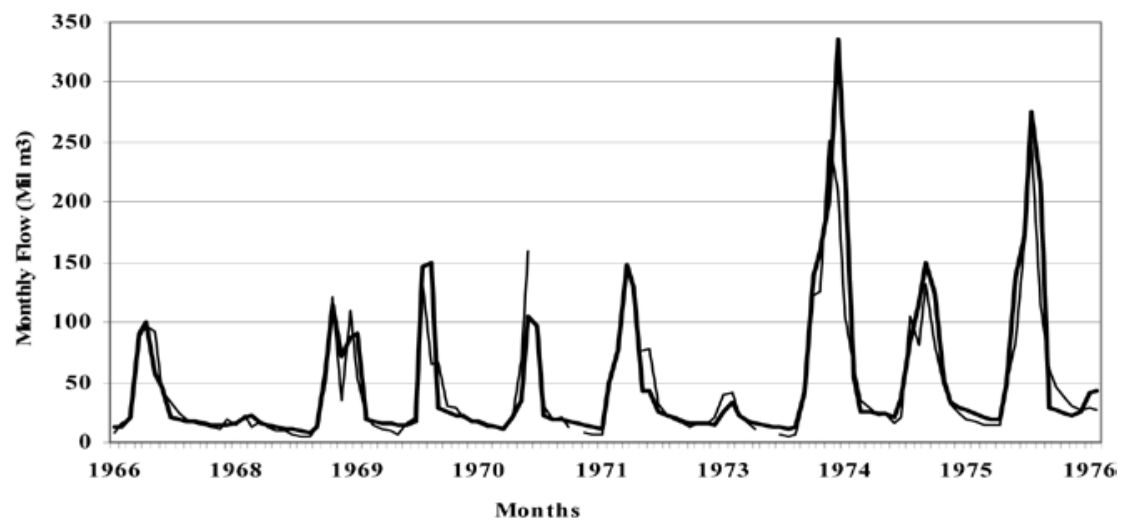

moisture. This distribution is assumed to be a function of basin slope and soil drainage properties which determine the rates and patterns of moisture re-distribution after a storm event.

In the case of South Africa, the estimated parameters were often quite different from the WR90 regionalised parameters which have become 'conventional wisdom'. However, the revised simulation results were similar and frequently better. In the non-South African basins the results of model simulations were satisfactory, suggesting that the estimation procedure is quite robust. The revised model parameterisation procedure should contribute to more consistent and objective parameter quantification and improve the potential to apply the model in ungauged basins without reliance on calibration results. These initial results suggest that the new approach has a great deal of potential. The next step would be to extend the same approach to estimate the rest of the free parameters of the model. The remaining parameters are mostly associated with interception and evapotranspiration processes and are expected to be related to basin vegetation cover and rooting depth characteristics.

In spite of the relatively encouraging results, there are a number of sources of potential uncertainty related to the availability, within the Southern African region, of the appropriate physical basin data and the disparities in the spatial scales and the levels of detail of

Results of model simulations using the revised parameter estimation procedures compared to the observed flow for the Honde River in Mozambique at E73 (A) and the Little Boesmans River in South Africa at V7H012 (B).

In the other parts of the region where no regional parameters exist, model simulations were compared with observed flows. The results show that the revised parameter estimation procedures are satisfactory (see e.g. Fig. 6A). The means of the simulated flows for all the basins were within $+/-10 \%$ of the mean of the observed flows with the $\mathrm{CE}$ values of both the untransformed and the log-transformed values at least 0.60 .

\section{Discussion and conclusion}

The approach has demonstrated the potential of using measurable physical basin attributes to directly quantify the soil moisture accounting, runoff, recharge and infiltration parameters of the Pitman model. Soil type and texture, geology, topography and hydrometeorological data have been used to develop the parameter estimation procedures. Deep, well- drained soils and gentle slopes have the capacity to hold more water resulting in a higher value for ST while the shallow soils more characteristic of steeper headwater basins have lower ST values. The rate and amount of interflow (FT) is a function of the drainage density, basin slope and saturated hydraulic conductivity of the soil, as well as the transmissivity of the underlying geological formation of the unsaturated zone. Variations in runoff with mean basin moisture content will depend on the spatial distribution of soil the data currently available. It is possible, however, that with GIS and remote-sensing technologies, these data may soon be more widely available. Widespread application of this revised approach may prompt improvements in the availability and accessibility of physical basin data.

Given the sound physical hydrology basis of the Pitman model and its applicability in diverse geo-bio-climatic conditions, the authors are confident that the methods proposed in this study, though based on a number of selected basins chosen exclusively from the southern part of the SADC region, would be equally applicable throughout the region and beyond.

\section{Acknowledgements}

This study was made possible by a bursary provided to the principal author by the Institute for Water Research (IWR) and a scholarship from the National Research Foundation (NRF) (Contract No. SFH2006102300106).

\section{References}

AO T, ISHIDAIRA H, TAKEUCHI K, KIEM AS, YOSHITARI J, FUKAMI K and MAGOME J (2006) Relating BTOPMC model parameters to physical features of MOPEX basins. J. Hydrol. $\mathbf{3 2 0}$ 84-102. 
BERGSTROM S (2006) Applications of the HBV hydrological model in prediction in ungauged basins. In: Large Sample Basin Experiments for Hydrological Model Parameterization: Results of the Model Parameter Experiment MOPEX. IAHS Publ. 307. 97-107.

BEVEN KJ (1993) Prophecy, reality and equifinality in distributed hydrological modelling. Adv.Water Resour. 16 (1) 41-51.

BEVEN J (2001) Rainfall-Runoff Modeling: A Primer. Wiley \& Sons Ltd, Chichester, West Sussex, England.

BOUGHTON W and CHIEW F (2006) Estimating runoff in ungauged catchments from rainfall, PET and the AWBM model. Environ. Model. Software 22 (4) 476-487.

CHIEW FHS and SIRIWARDENA L (2005) Estimation of SYMHYD parameter values for application in ungauged catchments. In: Zerger A and Argent RM (eds.) Proc. MODSIM 2005 Int. Congress on Modelling and Simulation. Modelling and Simulation Society of Australia and New Zealand. Held in December 2005, Melbourne, Austraulia. pp. 2883-2889. ISBN: 0-9758400-2-9. http://www. mssanz.org.au/modsim05/papers/chiew 2.pdf

COSBY BJ, HORNBERGER G, CLAPP RB and GINN TR (1984) A statistical exploration of the relationships of soil moisture characteristics to the physical properties of soils. Water Res. Resour. 20 (6) 682-690.

DWAF (Department of Water Affairs and Forestry) (2005) Groundwater Resource Assessment II. Pretoria, South Africa.

FRANKS S (2002) Integrating models, methods and measurements for prediction in ungauged basins. In: Proc. Predictions in Ungauged Basins: PUB Kick-Off. PUB kick-off meeting held 20-22 November 2002 in Brasilia, Brazil. IAHS Publ. 309.13-21

HUGHES A (1982) Conceptual Catchment Model Parameter Transfer Studies using Monthly Data from the Southern Cape Coastal Lakes Region. HRU Report No. 1/82. Department of Geography, Rhodes University, South Africa.

HUGHES DA (1997) Southern African 'FRIEND' - The Application of Rainfall-Runoff Models in the SADC Region. WRC Report No. 235/1/97. Water Research Commission, Pretoria, South Africa.

HUGHES DA (2004) Incorporating ground water recharge and discharge functions into an existing monthly rainfall- runoff model. Hydrol. Sci. J. 49 (2) 297-311.

HUGHES DA, ANDERSSON L, WILK J and SAVENIJE HHG (2006) Regional calibration of

the Pitman model for the Okavango River. J. Hydrol. 331 30-42

HUGHES D A and SAMI K (1994) A semi-distributed, variable time interval model of

catchment hydrology - structure and parameter estimation procedures. J. Hydrol. 155 265-291.

INTERNATIONAL WATER MANAGEMENT INSTITUTE (IWMI) (2007) IWMI Online Climate Summary Service. Www.lk.iwmi. org/WAtlas/AtlasQuery.htm
MAZVIMAVID (2003) Estimation of Flow Characteristics of Ungauged Catchments. Wageningen University Ph.D. Thesis and International Institute for Geo- Information and Earth Observation. ITC Dissertation No. 107. Enschede, The Netherlands.

MERZ R and BLOSCHL G (2004) Regionalization of catchment model parameters. J. Hydrol. 287 95-123.

MIDGLEY DC, PITMAN WV and MIDDLETON BJ (1994) Surface Water Resources of South Africa 1990, Volumes I to IV. WRC Report No. 298/1.1/94 to 298/6.2/94. Water Research Commission, Pretoria, South Africa.

MOORE RJ (1985) The probability-distributed principle and runoff production at point and basin scales. Hydrol. Sci. J. 30 (2) 273-297.

NATHAN RJ and MCMAHON TA (1990) Identification of homogeneous regions for the purposes of regionalization. J.Hydrol. 121 217-238.

OYEBANDE L (2001) Water problems in Africa - how can sciences help? Hydrol. Sci. J. 46 (6) 947-961.

PITMAN WV (1973) A Mathematical Model for Generating Monthly River Flows from Meteorological Data in South Africa. HRU Report No. 2/73. Hydrological Research Unit, Univ. of the Witwatersrand, Johannesburg, South Africa..

RAWLS WJ, BRAKENSIEK DL and SAXTON KE (1982) Estimations of soil water properties. Trans. ASAE 5 (5) 1316-1320.

SCHULZE RE, HUTSON JL and CASS A (1985) Hydrological characteristics and properties of soils in Southern Africa 2: Soil water retention models. Water $S A 11$ (3) 129-136.

SIVAPALAN M, TAKEUCHI K, FRANKS SW, GUPTA VK, KARAMBIRI H, LAKSHMI V, LIANG X, MCDONNELL JJ, MENDIONDO EM, O'CONNELL PE, OKI T, POMEROY JW, SCHERTZER D, UHLEBROOK S and ZEHE E (2003) IAHS decade on prediction in ungauged basins (PUB), 2003-2012: Shaping an exciting future for the hydrological sciences. Hydrol. Sci. J. 48 (6) 857-880.

SWECO (2004) Development of the Pungwe River Basin Joint Integrated Water Resources Management Strategy. Pungwe Project Monograph Report, SWECO, Stockholm, Sweden

US DEPARTMENT OF AGRICULTURE SOIL CONSERVATION SERVICE (1969) Engineering Field Manual for Conservation Practices. Washington DC, USA.

WAGENER T, HOGUE T, SCHAAKE J, DUAN Q, GUPTA, H, ANDREASSIAN V, HALL A and LEAVESLEY G (2006) The Model Parameter Estimation Experiment (MOPEX): Its structure, connection to other international initiatives and future directions. In: Large Sample Basin Experiments for Hydrological Model Parameterization: Results of the Model Parameter Experiment (MOPEX). IAHS Publ. 307 339-346. 
Available on website http://www.wrc.org.za ISSN 0378-4738 = Water SA Vol. 34 No. 2 April 2008

ISSN 1816-7950 = Water SA (on-line) 